\title{
Linking models of land use, resources, and economy to simulate the development of mountain regions (ALPSCAPE)
}

\section{Journal Article}

Author(s):

Lundstroem, Corinne; Kytzia, Susanne; Walz, Ariane; Grêt-Regamey, Adrienne (D); Bebi, Peter

Publication date:

2007

Permanent link:

https://doi.org/10.3929/ethz-b-000066345

Rights / license:

$\underline{\text { In Copyright - Non-Commercial Use Permitted }}$

Originally published in:

Environmental Management 40(3), https://doi.org/10.1007/s00267-005-0342-8 


\title{
Linking Models of Land Use, Resources, and Economy to Simulate the Development of Mountain Regions (ALPSCAPE)
}

\author{
Corinne Lundström · Susanne Kytzia • \\ Ariane Walz · Adrienne Gret-Regamey . \\ Peter Bebi
}

Received: 2 November 2005/ Accepted: 2 February 2007

(C) Springer Science+Business Media, LLC 2007

\begin{abstract}
We present a framework of a scenario-based model that simulates the development of the municipality of Davos (Swiss Alps). We illustrate our method with the calculation of the scenario for 2050 " Decrease in subsidies for mountain agriculture and liberalization of markets." The main objective was to link submodels of land-use allocation (regression-based approach), material and energy flows submodels (Material and Energy Flux Analysis), and economic submodels (Input-Output Analysis). Letting qualitative and quantitative information flow from one submodel to the next, following the storyline describing a scenario, has proven to be suitable for linking submodels. The succession of the submodels is then strongly dependent on the scenario. Qualitative information flows are simulated with microsimulations of actor choices. Links between the submodels show different degrees of robustness: although the links involving microsimulations are the weakest, the uncertainty introduced by the land-use allocation model is actually advantageous because it allows one possible change in the landscape in the future to be simulated. The modeling results for the scenario here presented show that the disappearance of agriculture only marginally affects the region's factor income, but that the consequences for the self-sufficiency rate, for various
\end{abstract}

C. Lundström $(\bowtie) \cdot$ A. Walz · A. Gret-Regamey ·

P. Bebi

Research Unit Ecosystem Boundaries, WSL: Swiss Federal

Institute for Forest, Snow and Landscape Research, CH-7260

Davos, Switzerland

e-mail: c.lundstroem@bluewin.ch

S. Kytzia · A. Gret-Regamey

Regional Resource Management, Institute for Spatial and Landscape Planning, Swiss Federal Institute for Technology, CH-8092 Zürich, ETH landscape-related indicators and ecosystem services, and for the economy in the long term may be considerable. These benefits compensate for agriculture's modest direct economic value. The framework presented can potentially be applied to any region and scenario. This framework provides a basis for a learning package that allows potential detrimental consequences of regional development to be anticipated at an early stage.

Keywords Agriculture - Input-output analysis · Integrated model $\cdot$ Land-use allocation $\cdot$ Material and energy-flux analysis - Scenario

Understanding regional development is a complex problem that requires integration of knowledge from numerous disciplines including ecology, economics, and the social sciences. This is fundamental to understanding how a region will develop in response to environmental and socioeconomic changes and how policy and management decisions will affect these outcomes. One of the greatest challenges for interdisciplinary research is therefore to understand the driving forces behind regional development and to propose useful future development strategies. Scenario-based modeling, especially if done in a spatially explicit, integrated, and multiscale manner, is a promising technique for the projection of alternative pathways of spatial development into the future (Veldkamp and Lambin 2001). Combined with relevant indicators (e.g., Swiss Federal Statistical Office 1999a, Swiss Agency for the Environment, Forests and Landscape 2002), such scenario models allow the sustainability of different development pathways to be tracked. Such integrated models could be highly valuable for understanding alternative future development options better (von Ballmoos and Bebi 2003), 
particularly in mountain regions that are vulnerable to environmental changes (Beniston 2000).

Over the past decades, there have been several attempts to integrate social science and biophysical models (e.g., Leontief and others (1977), Braat and van Lierop (1987)). Model approaches that relate economic activity or resource consumption to land use often describe the anthroposphere as a network of processes linked by physical and financial flows (e.g., Krausmann and others (2004)). Useful flow modeling approaches are input-output analysis (IOA) (Leontief and others 1977), material and energy flow analysis (MFA/EFA) (Baccini and Bader 1996), and combined models of both approaches (Kytzia and Nathani 2004, Kytzia and others 2004).

Differences in spatial and temporal resolution still limit how well the economic and resource models can be integrated with spatially explicit land-use models (Meyer and Turner 1994). The socioeconomic input is often used as an explanatory variable, supplying information about demand for a specific land-use type. Conversely, spatially explicit land-use models provide information on the supply of specific resources, which can then be linked back to economic and resource models. These interrelationships between economy, resource management, and land use can either be based on a number of more-or-less explicitly formulated assumptions, or can be addressed by simulating actor choices and agents' behavior (e.g., consumption patterns or production practices) (Alberti and Waddell 2000).

In this paper, we present the concept of a modeling framework to assess regional development in mountain areas based on an economic, a resource, and a land-use model. This framework is planned as a tool that i) identifies the relevant driving forces behind regional development; ii) links models of the regional economy and material and energy balance with landscape dynamic models, and iii) visualizes and evaluates different scenarios of possible regional development. Finally, this model should provide a basis for planning regional development, and for developing practical applications of these scenarios as public learning tools or games.

We developed the framework in the municipality of Davos in southeast Switzerland (hereafter referred to as Landschaft Davos, Figure 1) and explored scenarios for how Davos could develop if subsidies for mountain agriculture were decreased and the market liberalized (scenario-based future state for the year 2050). Davos faces the challenge of being one of the largest winter-tourist resorts in the Alps (12,277 inhabitants and 25,000 guest-beds in 2000) and at the same time maintaining its attractiveness for permanent residents and traditional tourism in a cultural region (unlike tourism in a city or adventure in the wild). This attractiveness depends, in our opinion, partly on fos- tering the cultural landscape, natural areas, and biodiversity, which can be influenced by continuing the agricultural activity in the region.

As a first step in the framework, the current state (year 2000) of the Landschaft Davos was simulated with the model. Then an extreme scenario was described for a possible future state (year 2050) in the form of a storyline (Walz and others 2007), which is easy to follow and dramatic. The storyline is based on qualitative local system knowledge, gathered during workshops with representatives in the region, following a technique that combines formative and intuitive scenario development (Scholz and Tietje 2002, Wiek and others 2006). Only one scenario is presented in this paper, but the model has also been applied to two other relevant scenarios for the mountain region of Davos. The first scenario has to do with accelerated climate change and its impact on tourist needs and the skiing industry, whereas the second involves intense tourism development with urban expansion taking place due to a major crowd-drawing event, which is sometimes used as a strategy in the tourist industry (Grêt-Regamey and others 2007, Grêt-Regamey and others in press, Grêt-Regamey and others in press, Kytzia and others in press).

The first part of this paper introduces the methodological approach behind the model ALPSCAPE and the four categories of submodels. Our methodological approach is illustrated by the scenario Decrease in subsidies for mountain agriculture and liberalization of markets, which assumes a drastic decrease in public subsidies for mountain agriculture and a liberalization of the market. The paper subsequently describes how the elements in the different submodels are intra- and interrelated in an integrated framework, and presents a selection of results from the example scenario, which we use to illustrate the capacities of the framework. The aim of this paper is thus to address the following questions:

1. How can models of a mountain regional economy, material and energy balance, and landscape dynamics be successfully linked in an integrated framework?

2. Can the relevance of the agricultural sector of a mountain region be assessed, not only for economic added value and jobs, but also for other values, such as those relating to society, the landscape, or the economy in the long term?

\section{Data Sources}

Land-use data is available on a $100-\mathrm{m} \times 100-\mathrm{m}$ grid from two surveys made in 1985 and 1997 (Swiss Federal Statistical Office 1999b), and from an analogous survey based on aerial photographs from 1954. On the same raster 
Fig. 1 Digital topography map of the study area Landschaft Davos. Dots show housing and infrastructure according to the land-use survey of 1997

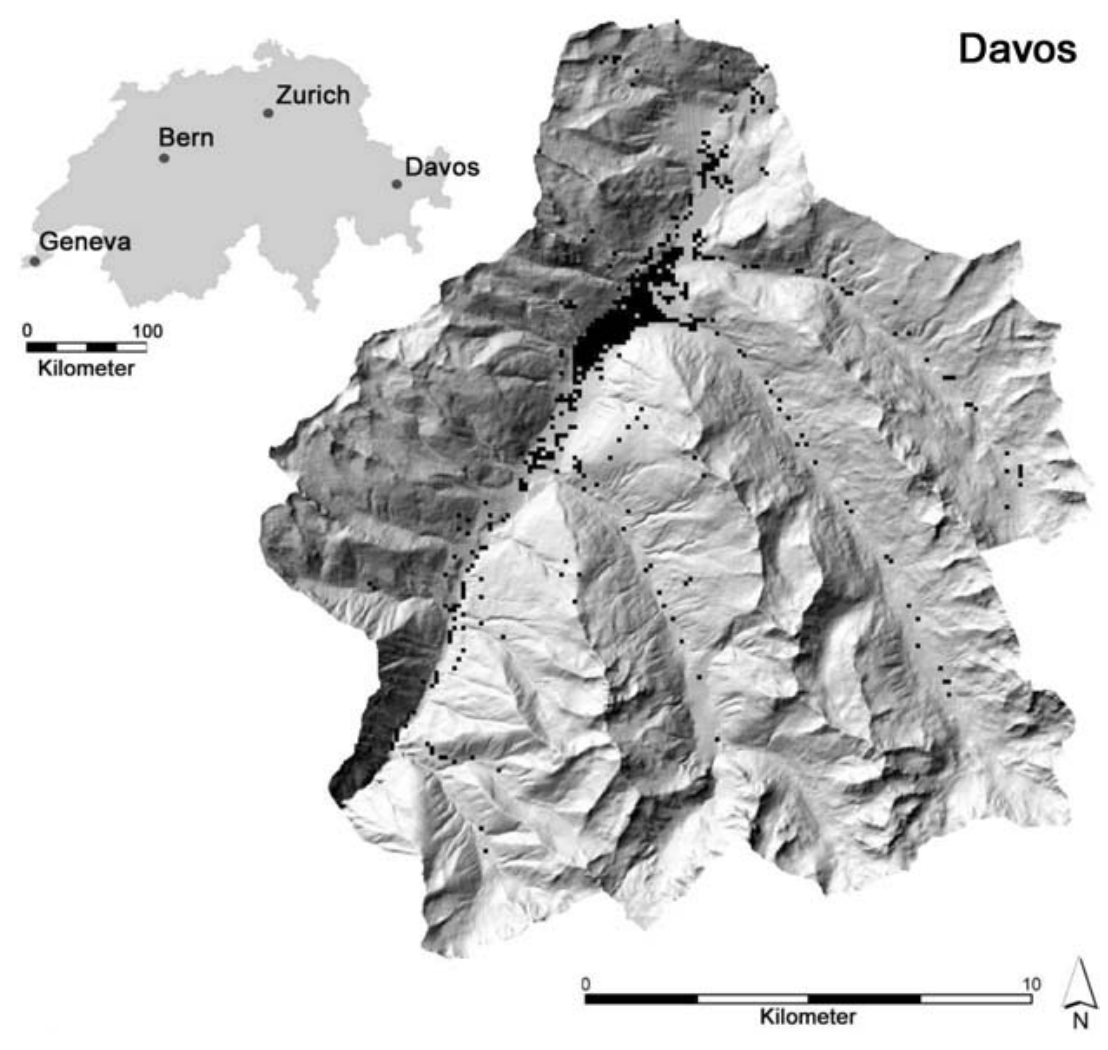

tourism (hotel and restaurants, mountain railways) and to the permanent population (transport, banks, insurances, etc.). Also included are their land and energy consumption (oil, electricity, and wood), in absolute quantities (hectares and gigajoules, respectively), and how they contribute to the economy (Fig. 2). In the scenario Decrease in subsidies for mountain agriculture and liberalization of markets, the central industry is agriculture (marked bold in Fig. 2). It affects local food production and consumption, the local economy, the employment of locals, and local resources (land areas) (in gray in Fig. 2). The calculated demand for certain land-use types is used as input for the land-use allocation submodel (LUA). At the end of the flow chart (on the right), indicators served to collate and summarize the information. The indicators resulting from the scenario are given in Table 3 and presented in the results.

The submodels pick up information, as input data, contained in the elements listed in Table 1, and deliver information for further submodels (output). We distinguish between three types of submodels based on different methodological approaches (Fig. 3):

(A) Process-based submodels of the economy (IOA) are used to model commodity flows such as imports, factor income, consumption, investments, and exports in monetary units (Kytzia and Nathani 2004; Kytzia and others 2004). IOAs allow key economic processes to be identified, as well as chains of economic value 


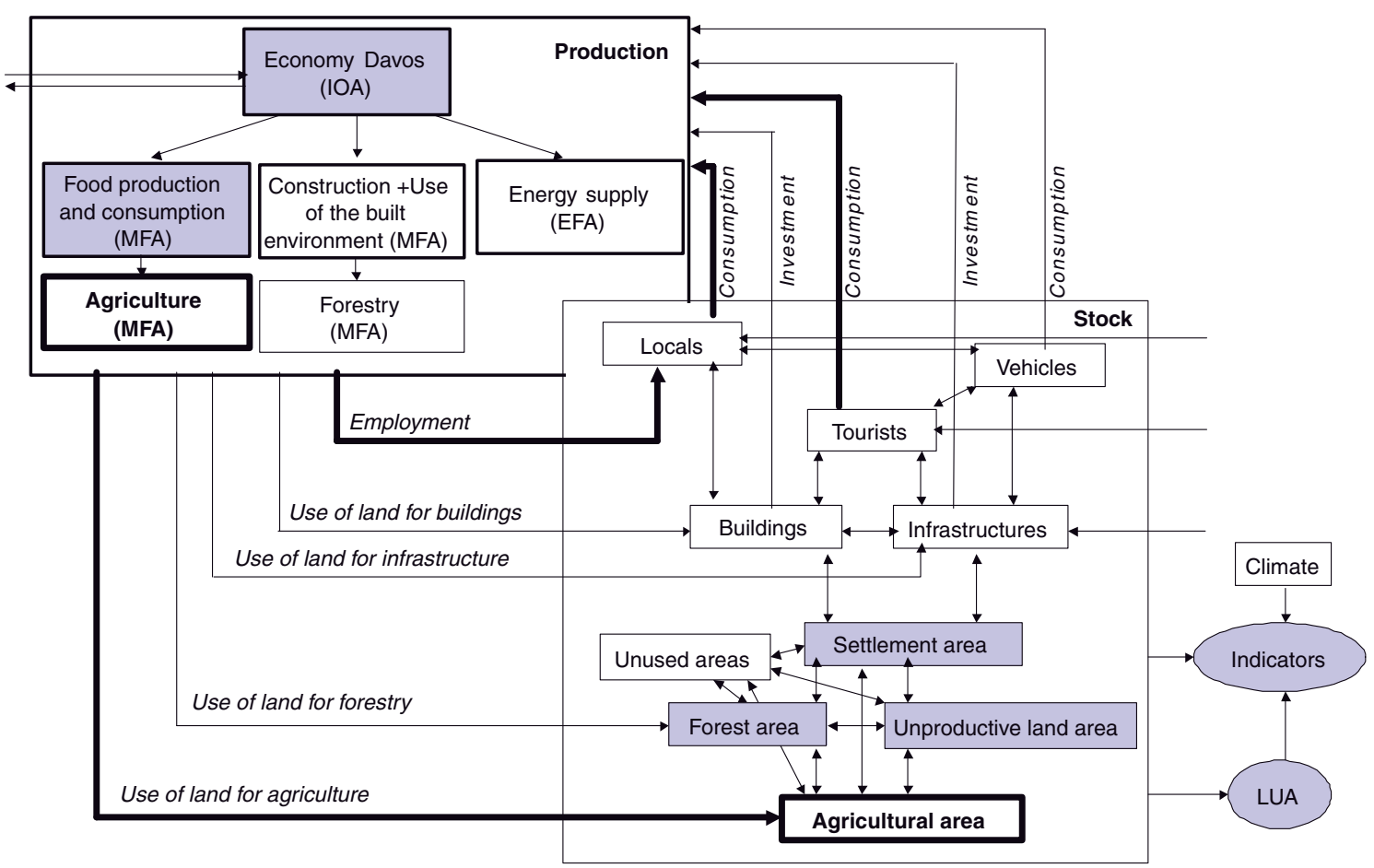

Fig. 2 Elements of industry, energy, the economy, and land use included in the example system. In italics are the activities relating the production to the stocks. IOA $=$ Input-Output Analysis, MFA =
Material-Flux Analysis, EFA = Energy-Flux Analysis, LUA = LandUse Allocation

the energy content of the materials mentioned above and is not related to land use. These submodels are defined on a lower level of aggregation than the IOA submodels (e.g., energy use in motor vehicles in EFA, instead of factor income generated by public transport in IOA). MFA/EFA allow the identification of the consequences of externalities, such as lifestyle (consumer baskets) or technological change, that affect productivity (e.g., a shift from conventional to organic agriculture) and thus the regional economy and resources fluxes. In our example, we calculated the MFA for food production and consumption chains, which includes the local agriculture products (submodels "Local Agriculture" and "Food", Table 1). This allowed us to calculate how much of the consumer needs (both local and tourists') can be met by domestic agriculture and to what extent the region depends on food produced elsewhere. This MFA also enables fodder production, cattle needs, and imports to be calculated.

(C) A spatially explicit, grid-based submodel is used to simulate future LUA. Model outcomes are land-use maps using the same 100-m lattice as the existing land-use data. Externalities include previous land use, topography, soil characteristics, accessibility, and spatial planning information. The LUA consists 
Table 1 The submodels, their type (IOA = Input-Output Analysis, MFA = Material-Flux Analysis, EFA = Energy-Flux Analysis, LUA = LandUse Allocation) and the elements included as input or output ( $\rightarrow$ indicates outputs)

\begin{tabular}{|c|c|c|}
\hline Submodels & Submodel types & Elements (see Figure 2) \\
\hline \multicolumn{3}{|l|}{ Non-spatially explicit } \\
\hline Individual transport & EFA & $\begin{array}{l}\text { Vehicles } \\
\text { Infrastructure } \\
\text { Population } \\
\text { Tourists } \\
\rightarrow \text { Energy supply }\end{array}$ \\
\hline Household energy & EFA & $\begin{array}{l}\text { Population } \\
\rightarrow \text { Energy supply }\end{array}$ \\
\hline Industry and trade energy & EFA & $\begin{array}{l}\text { Population } \\
\text { Tourists } \\
\rightarrow \text { Energy supply }\end{array}$ \\
\hline Local agriculture & MFA & $\begin{array}{l}\text { Agriculture } \\
\rightarrow \text { Agricultural area } \\
\rightarrow \text { Local food production }\end{array}$ \\
\hline Food & MFA & $\begin{array}{l}\text { Population } \\
\text { Tourists } \\
\text { Local food production } \\
\rightarrow \text { Food production and consumption }\end{array}$ \\
\hline Construction & MFA & $\begin{array}{l}\text { Population } \\
\text { Tourists } \\
\text { Buildings }\end{array}$ \\
\hline & & $\rightarrow$ Construction and use of the built environment \\
\hline Wood & MFA & $\begin{array}{l}\text { Forestry } \\
\text { Forest area } \\
\rightarrow \text { Construction and use of the built environment }\end{array}$ \\
\hline Economy & IOA & All elements \\
\hline Indicators & Evaluation & $\begin{array}{l}\text { All elements } \\
\rightarrow \text { (see Table } 3)\end{array}$ \\
\hline \multicolumn{3}{|l|}{ Spatially explicit } \\
\hline Land-use allocation & LUA & $\begin{array}{l}\rightarrow \text { Settlement area } \\
\rightarrow \text { Agricultural area } \\
\rightarrow \text { Forest area } \\
\rightarrow \text { Unproductive land } \\
\rightarrow \text { Unused areas }\end{array}$ \\
\hline Land-use map & Visualization & $\begin{array}{l}\rightarrow \text { Settlement area } \\
\rightarrow \text { Agricultural area } \\
\rightarrow \text { Forest area } \\
\rightarrow \text { Unproductive land } \\
\rightarrow \text { Unused areas }\end{array}$ \\
\hline
\end{tabular}

of two major steps: Transition probabilities for individual sites are first determined with logistic regressions, which consider the externalities spatial arrangement and site properties as explanatory variables. Simulated land-use maps for future scenarios are then derived through a stochastic procedure (Walz and others in press, Walz 2006). In our example, the LUA submodel identifies the agricul- tural land most suitable for further cultivation and the plots that are most likely to be abandoned, and determines future LUA for the suitable land.

(D) Submodels of evaluation, monetary valuation, and visualization: A set of indicators was selected, based on existing lists of indicators (e.g., Swiss Federal Statistical Office and Swiss Agency for the Environment, Forests and Landscape 2003). These help 
Fig. 3 The different methodological approaches (A-D) of ALPSCAPE's modeling framework, with externalities and typical datatypes. MFA = Material-Flux Analysis, EFA = Energy-Flux Analysis, LUA = Land-Use Allocation

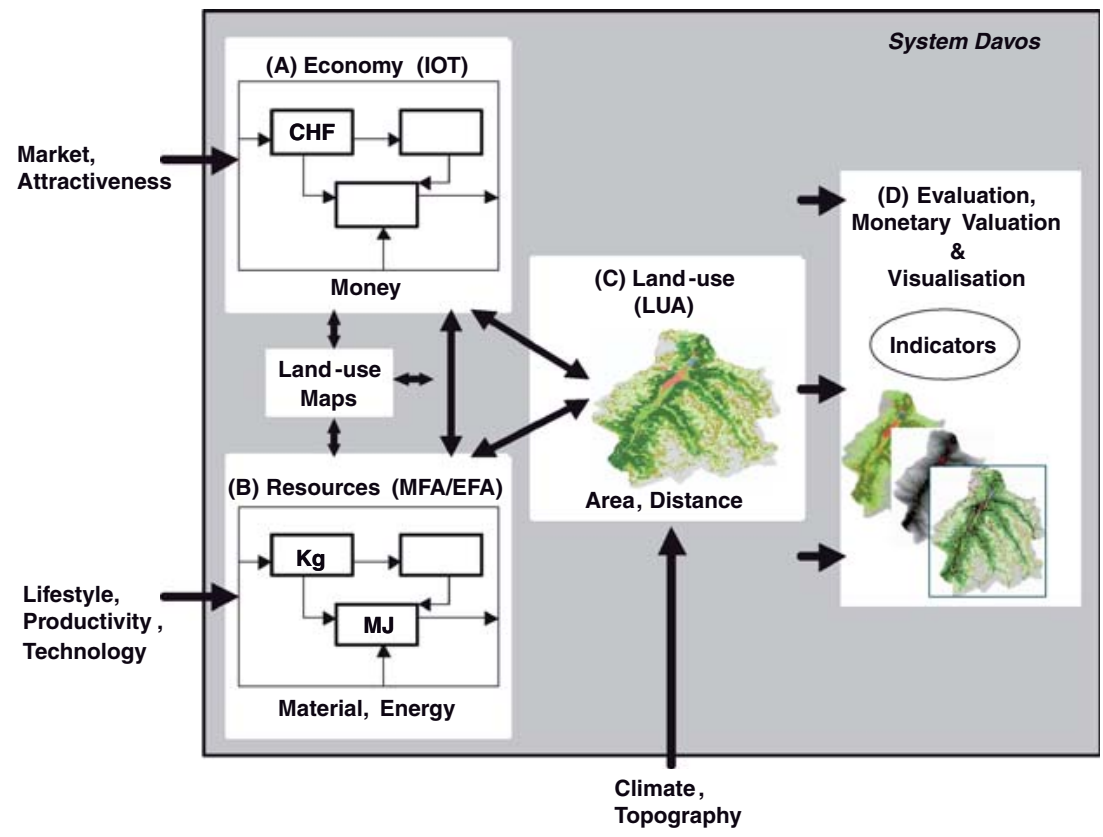

the tracking of key types of capital in the economy, resources, and land needed by future generations, and, as a result, provides a basis for evaluating the sustainability of the region's development. The submodel includes global indicators for the Landschaft Davos and spatially explicit indicators, giving a value for each 25,400 1-hectare pixel of the Landschaft Davos and leading to 2-D maps of indicators (Table 3 and Fig. 7). The indicators cannot be compared with each other directly because they refer to different units and do not lead to a unique, aggregated value. In addition to these global indicators, we calculated a set of spatially explicit ecosystem services, and integrated them into this framework to measure the change in monetary value of several functions of the landscape (Grêt-Regamey and others 2007, GrêtRegamey and others in press, Grêt-Regamey and others in press).

\section{Links Between Submodels}

The submodels are integrated into one single model by letting the information flow from one to the other following the succession defined in the storylines describing the scenarios, for example, that by Walz and others (2007). Preliminary estimates can be done with single submodels in order to identify the relevant elements that should be included in the scenarios, or to adjust parameters coming from different data sources. The information is either quantitative (output of a submodel or original data) or qualitative (e.g., a tendency discovered in a preliminary analysis or information gathered during local system knowledge process).

The quantitative information flows are illustrated in Fig. 2. They occur mostly between the submodels of IOA and MFA/EFA. These submodels pick up the necessary data in the stock of actors (Locals, Tourists), of infrastructure (Buildings, Infrastructure, Vehicles) and of land area (Settlement area, Agricultural area, Forest area, Unproductive land, and Unused area) to calculate, with deterministic relationships, the production and consumption of money, material, and energy. Production is calculated on the basis of the productivity of the processes observed (grass yield, milk and meat production per animal, timber yield, energy yield, employment opportunities, rate of building and infrastructure development) and the stocks of land resources (Agricultural area, Forest area, Settlement area). Consumption is calculated according to the stock of users (Population, Tourists, Vehicles, Buildings, Infrastructure) and the specific consumption of the goods in each process (consumption of grass, dairy and meat products, wood, energy for heating, living, producing, transporting). The flows of information between the land areas and the LUA submodel lead to stochastic relationships, because the LUA submodel is based on probabilistic uncertainties (Walz and others in press, Walz 2006).

Qualitative information flows are simulated with microsimulation of actor choices, similar to the approach taken by, for example, Waddell and others (2003) for urban development. These models operate at the level of the individual or group. They allow behaviors to be simulated that cannot be reduced to equations (e.g., how farmers react 
Table 2 Farming structure today and in the scenario Decrease in subsidies for mountain agriculture and liberalisation of markets (A and B as two variants)

\begin{tabular}{lccc}
\hline Number of farms & & & \\
\hline Type of farm & Davos today year 2000 & Scenario A year 2050 & Scenario B year 2050 \\
\hline Small farm (part-time farming) with dairy cows & 6 & 0 & 0 \\
Small farm (part-time farming) with beef cattle & 1 & 7 & 3 (Hobby) \\
Small farm (part-time farming) with sheep, goats, and horses & 6 & 8 & 3 (Hobby) \\
Traditional farm with dairy cows & 24 & 0 & 0 \\
Traditional farm with beef cattle & 2 & 0 & 0 \\
Traditional farm with sheep, goats, and horses & 2 & 0 & 0 \\
Traditional farm, collective farming (dairy cows and beef cattle) & 1 & 0 & 0 \\
Traditional farm with dairy cows and milk preparation & 0 & 4 & 0 \\
Organic farm with dairy cows & 27 & 0 & 0 \\
Organic farm with beef cattle & 4 & 0 & 0 \\
Organic farm with sheep, goats, and horses & 1 & 0 & 0 \\
Organic farm with dairy cows and milk preparation & 1 & 0 & 0 \\
Organic farm with beef cattle and meat preparation & 1 & 1 & 6 \\
Total & 76 & 20 &
\end{tabular}

to the suppression of subsidies, how investors decide on investments in businesses and buildings, how locals react to changes affecting their quality of life, how tourists react to climate change and changes in the leisure activities offered, or how tourists choose where to stay). Each actor (e.g., farmers, investors, locals, or tourists) is categorized according to characteristic values for variables describing aspects of their lifestyle (e.g., distance traveled by car, bus, and/or train per day, or number of people living in the household), ownership (e.g., type of farm, Table 2), and spending power.

For the scenario Decrease in subsidies for mountain agriculture and liberalization of markets, qualitative information defines the externalities and farmers' choices, before quantitative models calculate the consequences of these on the different domains included in the model (Fig. 4). This crucial step is worth a detailed description: Once the external hypotheses are set (Market and subsidies, Consumer behavior), a microsimulation of farmers' choices, in the form of a chain of rules, defines the structural changes in agriculture occurring after these external hypotheses (e.g., abandon the farm, change farming practices, or merge farms) (Fig. 5).

The farm types were identified in two steps: first, a principal component analysis was operated on the 81 original farms, followed by a classification by type and amount of production. The number of farms of each type that results is introduced as input into the local agriculture submodel. Outputs of this submodel are, for each farmer type, the production volume (essentially eggs, milk, and meat products) and the required land. For each farmer type, the number of cattle of each type and the specific production levels (egg, milk, or meat production of each animal) remain in the scenarios as today. The production volume is used further in the MFA and set against food consumption in the submodel "Food" to calculate the degree of regional self-sufficiency. At the same time, the production volume is used as input for the submodel "Economy,"' transformed into monetary value and used to calculate the imports of agricultural products. The land required for production is used as input in the LUA submodel to simulate a possible future landscape (Walz 2006).

\section{Scenario Storyline}

The storyline of the scenario Decrease in subsidies for mountain agriculture and liberalization of markets, described in detail in Walz and others (2007), is based on the following main assumptions (ovals in Fig. 4):

Market and subsidies: It is assumed that subsidies will be totally suppressed in 2011, when the new Swiss Agricultural Policy 2011 (24 2005) comes into force. Furthermore, it is assumed that the European market will then be totally liberalized.

Consumer behavior: Consumer behavior with respect to local, expensive products is an uncertainty in the scenario. The variation of this dimension leads to two variants: Scenario A assumes that locals and tourists will view local products positively and that demand for these products will increase despite higher prices. Scenario B assumes that demand will decrease drastically and that local, expensive products will not be commercially viable in future. 
Fig. 4 Flow of information in the scenario Decrease in subsidies for mountain agriculture and liberalization of markets. The ovals indicate the assumptions made for the scenario (see text). The arrows indicate the submodels as listed in Table 1. The rectangles indicate submodel inputs and outputs. I = Indicators, LUA = Land-Use Allocation

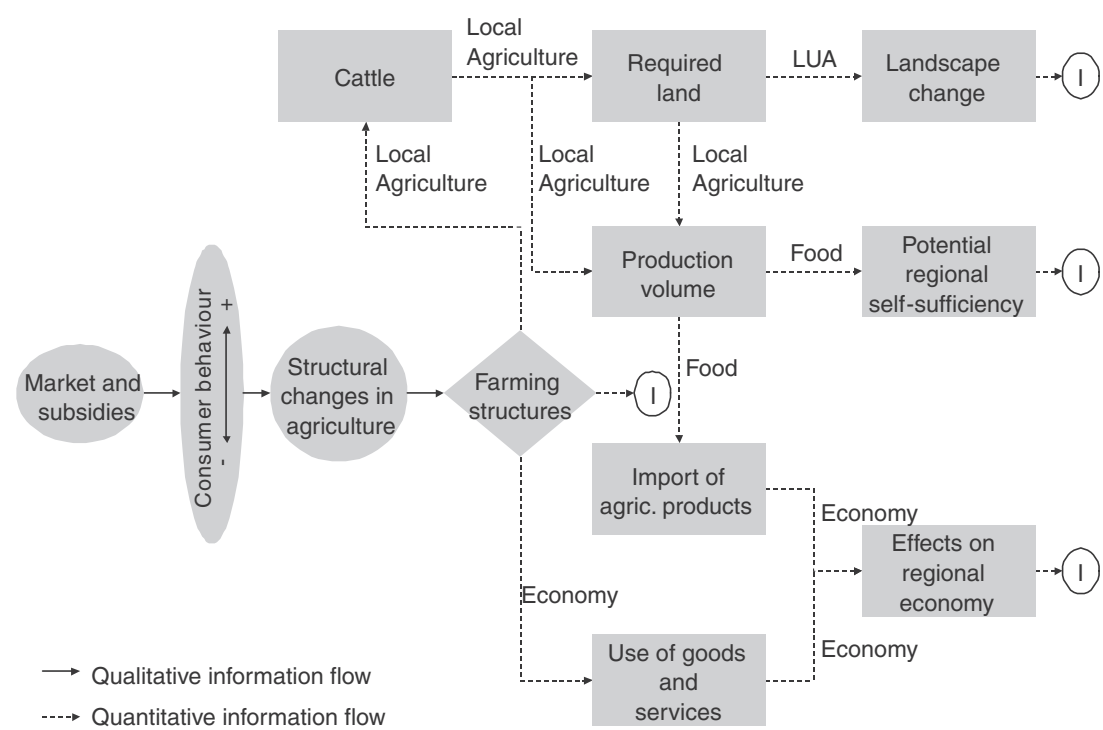

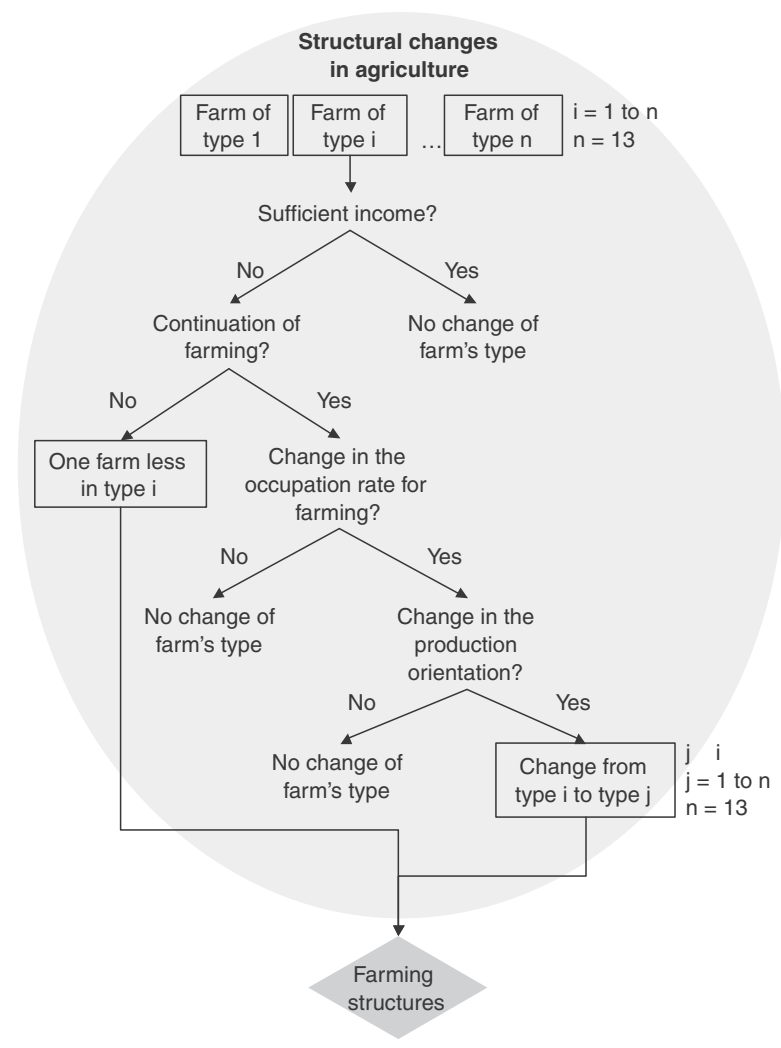

Fig. 5 Chain of rules for the oval "Structural changes in agriculture" of Figure 4, for the scenario Decrease in subsidies for mountain agriculture and liberalization of markets

Structural changes in agriculture: The structural changes assumed to take place after 2011 are derived from observations from the past and from interviews and discussions with experts on mountain agriculture and with local farmers. These external information sources led to the assumption that the farmers' incomes will decrease drastically, and that many farmers will have to stop production or change their farming practices. We considered the decrease in the farmer's income as an externality (suppression of the subsidies), and did not calculate it explicitly as feedback from the model (unlike, e.g., changes in product prices, revenues from forestry, and changes in theeconomic value of land). The farming structure was assumed to shift toward just a few large, professionally run farms and some small farms concentrating on labor-extensive meat production with secondary, nonagricultural income. We reduced this information to a chain of rules describing the actor's (here the farmer's) decision, depending on their income, the decision to continue farming, the decision to change the time spent on farming, and the decision to change the orientation of production (Fig. 5).

The characteristic farming structures for the current state and for the two scenarios are summarized in Table 2. In the year 2000, the model includes 76 farms, which receive a total of 4.3 million Swiss Francs (CHF) in direct subsidies per year. The farms run by retired farmers were not included, because they do not get subsidies. Another five farms were excluded because of their untypical structure. In scenario A, only 20 farms remain. Fifteen of them are run by part-time farmers who employ less than one person-day, and who own beef cattle, sheep, goats, and horses. Dairy cows are too time-consuming for these farmers. One third of the traditional farms have merged, forming four traditional collective farms with dairy cows and milk processing (a type of farm that does not exist today), whereas the others have disappeared. Indeed, in order to be competitive with European milk, the cost of milk production has to be reduced, which means that the farms have to be larger. As the total production is 
reduced, the local dairy stops production (it is not profitable anymore), which is why the four farmers have to do their milk-processing together. Because of the relatively high production costs of organic products, only one organic farm producing meat remains, even though locals and tourists have positive attitudes toward local products. With meat production decreasing below a critical threshold, the slaughterhouse also disappears. Some of the imported meat is still prepared in Davos, which means that $30 \%$ of the jobs related to the meat industry can be retained in the region. In scenario B, only six hobby-farms remain, three of them with beef cattle (no dairy cows), and three of them with sheep, goats, and horses. We assume that these hobby-farms will not market their products commercially. Some superordinated externalities (population, tourist structure and number, land-use regulations, consumer baskets, and the specific production and land use on each farm for each farm type) are assumed to remain the same in scenarios A and B as today.

\section{Results}

Indicators of the key factors in the model of the Landschaft Davos currently are given in Table 3, which also shows the impacts of the scenario assumptions on the simulation outcome.

The Landschaft Davos presently is an attractive place to live; the factor income per inhabitant $(48,415 \mathrm{CHF} /$ year $)$ almost equals the Swiss mean (41,500 CHF/year). Although the ratio of imports to GDP (goods and services) is $47 \%$, which is higher than the Swiss mean $(39.9 \%)$, the ratio of exports to GDP is $29 \%$, which is much lower than the Swiss mean $(45 \%)$. This illustrates the dependence of the region on imports.

Land use in the Landschaft Davos is dominated by extensive agriculture, forests, or bare land, which make up $83.5 \%$ of the total area. Housing and infrastructure cover $2.2 \%$ of the total area, which is much lower than the Swiss average $(6.8 \%)$. The production of agriculture in Davos is limited because of the local climatic and topographic conditions. This leads to a more extensive production system than normal in Switzerland (smaller farms, less machinery, lower growth rates of grass). The self-sufficiency rate in food (calculated as the rate of biomass produced in Davos to biomass consumed) is $27 \%$, which is much lower than the Swiss average for dairy products (111\%), beef-meat (about 90\%), or eggs (47\%) (Maurer 2002). In terms of surface, the intensively exploited area (meadow) is sufficient to produce $28 \%$ of the dairy products, meat and eggs consumed in Davos. In comparison, the land used for the production of these goods in Switzerland produces $33 \%$ of the Swiss consumption.
The energy consumption per inhabitant in the Landschaft Davos is higher than the Swiss average (135 compared to $121 \mathrm{GJ} /$ inhabitant/year (SFOE 2000)), which could be partly due to the higher energy need for heating because of lower mean temperatures. What is unique to the region is that it produces $10 \%$ of its electricity consumption, mainly through hydropower.

We modeled current agriculture in the Landschaft Davos as a mix of 12 types of farms, with 76 farms in total (see Scenario Storyline section above), without geographically locating the farms and barns. We considered the agricultural land as a whole, without considering which plots belong to which farmer. In each farm, $87 \%$ to $89 \%$ of the land is extensively exploited. Most of it is summer pasture, located above the forests ( $96 \%$ to $99 \%$ ). The rest is exploited as pasture in the valley floor or as extensive meadow above the forests. Most of the agricultural activity happens on the meadows in the valley floor (11\% to $13 \%$ of the land).

In scenario A, 152 of the current 6474 jobs in the region will disappear $(-2.3 \%)$. The disappearance of the local dairy and slaughterhouse, and the decrease in commercialization of agricultural products imply a loss in the regional GDP of 9.5 million CHF $(-1.5 \%)$ and a loss in the factor income in the region of 7.8 million CHF $(-1.2 \%)$. If direct subsidies for farming are subtracted from the GDP, the loss in GDP is 5.2 million CHF $(-0.83 \%)$. An eventual commercialization of the additional 1740 ha forest (see below) might compensate for this loss, but is not included in the storyline of this scenario because it would not happen before 2050. The contribution of agriculture to the economy of the region, which is already low today, will decrease from $0.2 \%$ to $0.04 \%$ of the factor income. The factor income per inhabitant will fall from 48,415 CHF to 47,815 CHF, which is still higher than the current Swiss factor income mean.

The reduction in energy use $(-0.39 \%)$ would be proportional to the abandonment of farms, the dairy, and the slaughterhouse. This reduction might be balanced out by the additional energy used in importing of goods (not calculated). Agriculture products would be significantly reduced: from 4900 tons of milk to 1300; 168 tons of meat to $30 ; 1323$ livestock to 468 ; and 2.2 million eggs to 0.6 million. As a consequence, the self-sufficiency rate in food (calculated as the ratio of production, including production for export, to consumption) decreases drastically from $27.4 \%$ to $7.3 \%$, measured in biomass, and from $27.8 \%$ to $8.1 \%$, measured in land area. The ratio of imports to GDP increases slightly, whereas that of exports to GPD decreases, which illustrates the increasing dependence of the region on imports. The proportion of food products among all imports increases for the same reason, whereas the proportion of foods among exports falls to almost zero. Of 
Table 3 Relevant indicators used to evaluate the development of mountain regions for the scenario Decrease in subsidies for mountain agriculture and liberalisation of markets

\begin{tabular}{|c|c|c|c|c|}
\hline Indicator & Unit & $\begin{array}{l}\text { Davos today } \\
\text { year } 2000\end{array}$ & $\begin{array}{l}\text { Scenario A } \\
\text { year } 2050\end{array}$ & $\begin{array}{l}\text { Scenario B } \\
\text { year } 2050\end{array}$ \\
\hline \multicolumn{5}{|l|}{ Economy \& sociology } \\
\hline Regional gross domestic product (GDP) & $\begin{array}{l}\text { Million } \\
\text { CHF/year }\end{array}$ & 627.7 & 618.2 & 616.2 \\
\hline Import rate to GPD & $\%$ & 46.9 & 47.8 & 48.1 \\
\hline Proportion food products of all imports & $\%$ & 13 & 14 & 15 \\
\hline Export rate to GPD & $\%$ & 29.5 & 29.3 & 29.3 \\
\hline Proportion food products of all exports & $\%$ & 2 & 0.4 & 0 \\
\hline Factor income & $\begin{array}{l}\text { Million } \\
\text { CHF/year }\end{array}$ & 631.6 & 623.8 & 621.3 \\
\hline Proportion of factor income arising from agriculture & $\%$ & 0.2 & 0.04 & 0 \\
\hline Employment & $\begin{array}{l}\text { Full-time } \\
\quad \text { equivalent }\end{array}$ & 6474 & 6322 & 6314 \\
\hline Farmers & Number & 76 & 20 & 6 \\
\hline Farming structure & & See Table 2 & See Table 2 & See Table 2 \\
\hline Change in level of protection provided by forests against avalanches & $\mathrm{CHF} /$ year & & $+244,000$ & $+348,000$ \\
\hline Change in economic value of scenic beauty & $\mathrm{CHF} /$ year & & -7000 & -6200 \\
\hline \multicolumn{5}{|l|}{ Resources } \\
\hline Self-sufficiency rate in land area for food production & $\%$ & 27.78 & 8.05 & 1.21 \\
\hline \multicolumn{5}{|l|}{ Self-sufficiency rate in $\mathrm{kg}$ biomass } \\
\hline Food & $\%$ & 27.39 & 7.27 & 0.09 \\
\hline Fodder & $\%$ & 102 & 96 & 108 \\
\hline Self-sufficiency rate in electricity & $\%$ & 10.08 & 10.16 & 10.18 \\
\hline $\begin{array}{l}\text { Energy-use for traffic, household, community, agriculture and others, including } \\
\text { electricity and heating energy (primary energy) }\end{array}$ & GJ/year & $1,664,324$ & $1,657,865$ & $1,657,034$ \\
\hline Rate of renewable energy & $\%$ & 28.06 & 27.97 & 27.95 \\
\hline $\mathrm{CO}_{2}$ emissions by total energy use & $\mathrm{t} \mathrm{CO}_{2} /$ year & 69,653 & 69,547 & 69,546 \\
\hline $\begin{array}{l}\text { Change in economic value of habitat (potential habitat for the umbrella species } \\
\text { Tetrao urogallus) }\end{array}$ & $\mathrm{CHF} /$ year & & +5300 & +6000 \\
\hline Change in economic value of wood production & $\mathrm{CHF} /$ year & & -9100 & $-13,100$ \\
\hline \multicolumn{5}{|l|}{ Land-use } \\
\hline Land-use map & & see Figure 6 & see Figure 6 & see Figure 6 \\
\hline Area of each land-use category & & & see Figure 7 & see Figure 7 \\
\hline Forest area & ha & $6379 *$ & 8119 & 8186 \\
\hline Intensive agriculture area & ha & $998 *$ & 291 & 42 \\
\hline Extensive agriculture area & ha & $8445^{*}$ & 2042 & 329 \\
\hline Unproductive vegetation area & ha & $2416^{*}$ & 7659 & 9544 \\
\hline Housing and infrastructure & ha & $566^{*}$ & 639 & 703 \\
\hline Other: bare land/water & ha & $6418 * / 221 *$ & $6418 / 221$ & $6418 / 221$ \\
\hline
\end{tabular}

* indicates measured value

the original 1370 ha agricultural land and the 8070 ha summer pasture, $25 \%$ would still be exploited: 290 ha intensively (meadow) and 2000 ha extensively (pasture, extensive meadow, summer pasture).

In scenario B, agriculture will not contribute to the regional economy at all because the products (5.8 tons meat; 177 livestock; 3300 eggs) are not commercially marketed, and because the six hobby-farms do not provide paid jobs.
A total number of 160 jobs would be lost. The loss in the regional GDP is 11.5 million $\mathrm{CHF}(-1.8 \%)$ and the loss in the factor income in the region is 10.3 million $\mathrm{CHF}$ ($1.6 \%$ ). The proportion of factor income from agriculture is null. The self-sufficiency rate in food, from the remaining six hobby-farms, is negligible $(0.09 \%$ in biomass and $1.2 \%$ in surface). The replacement with import products probably does not even require additional infrastructure. There is no 


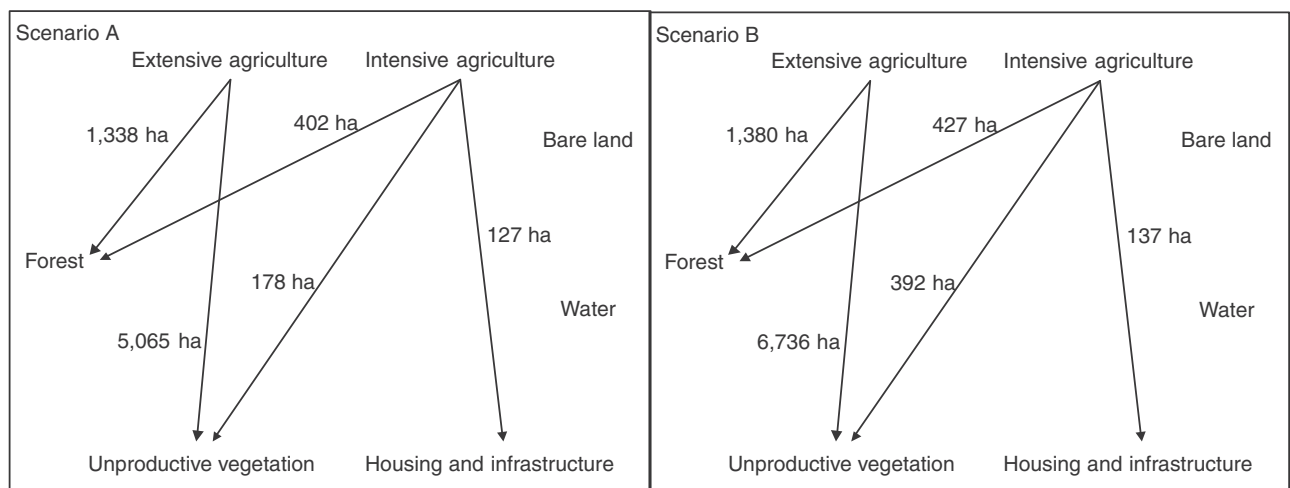

Fig. 6 Changes in land use between today and the simulations for the year 2050. Intensively exploited areas: meadow; extensively exploited areas: pasture, extensive meadow, summer-pasture

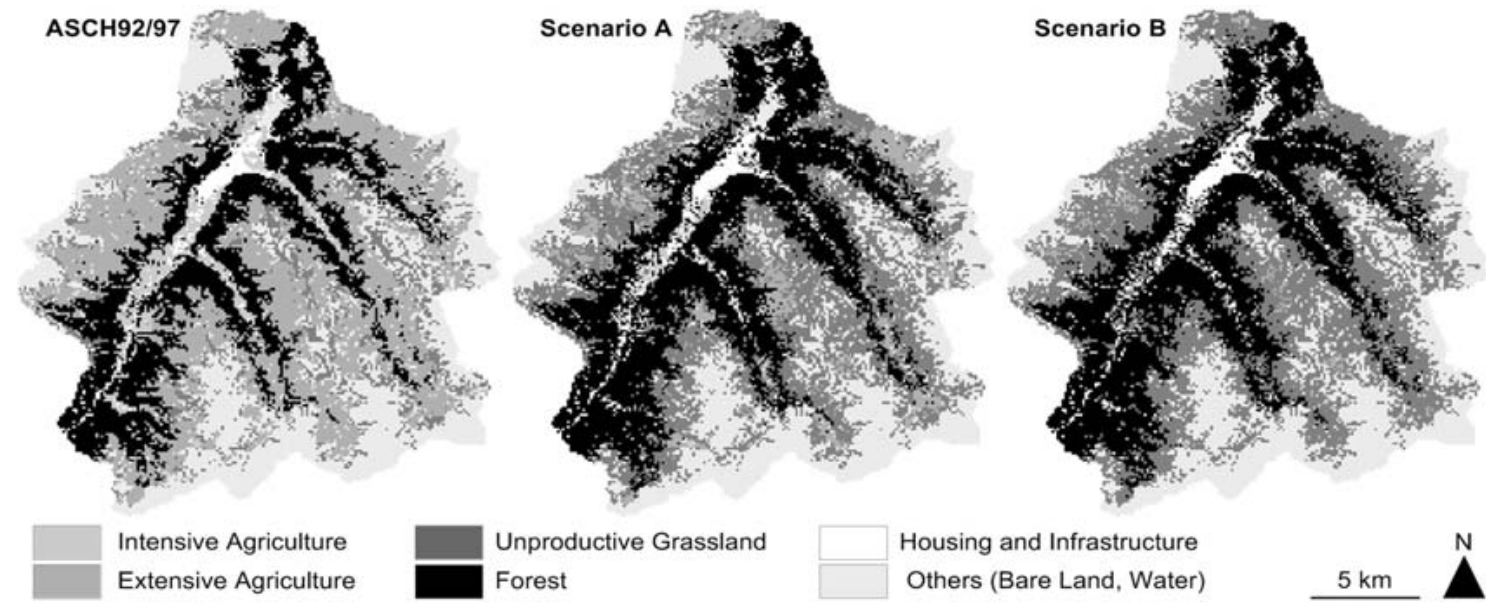

Fig. 7 Map of land use today (ASCH92/97: survey of 1997) and in the simulations for the year 2050

export of food, and imports have slightly increased. However, the region benefits from the remaining farming activity as far as the landscape is concerned: In the immediate neighborhood of the farms, 43 ha are still exploited, preserving an open landscape where forest expansion is prevented. The result is the kind of cultural landscape appreciated by tourists. Above the forest, 284 additional hectares would remain as summer-pasture land for cattle, which again prevents further natural forest expansion.

Large areas of the abandoned agricultural land (intensive and extensive) turn into unproductive vegetation and forest, and some into housing and infrastructure: $75 \%$ in scenario A, 97\% in scenario B (Fig. 6). The distribution of the land-use pattern is simulated with the allocation submodel (Fig. 7). The process of abandonment of extensively exploited areas is most striking as these areas, over the next 50 years, nearly all turn into unproductive areas (mostly above the forest) or into forest, depending, among other things, on the distance from the next forest and on the natural site conditions. In the valley floor, such unproductive areas are likely to turn into forest within a few decades if they are not located immediately next to a builtup area or in avalanche tracks, or used for housing and infrastructure, where the current land-use regulations allow this. Intensively exploited areas are assumed not to turn into extensively exploited areas, because this transition does not appear in the comparison of the land-use surveys of 1985 and 1997, on which the LUA model is based.

Both scenario variants A and B mean significant changes in ecosystem services (Table 3). For the four selected ecosystem services that we monetized in this project, the changes in these ecosystem services are positive, in the range of 233,200 CHF/year, if projected over the whole study area. This is about $0.04 \%$ of the GDP today, which is less significant than the $1.5 \%$ of the calculated changes in regional GDP with both scenarios variants.

The calculated changes in ecosystem services vary considerably for different types of ecosystem services and over the space of the topographically heterogeneous 
landscape (Table 3 and Grêt-Regamey and others in press). The expected forest expansion and densification in both scenario variants provide such benefits as avalanche protection in areas where the forest expands into potential avalanche release areas. The subsequent decrease in risk from avalanches saves between 244,000 CHF/year and $348,000 \mathrm{CHF} /$ year, which is the greatest change in an ecosystem service under the assumptions of the two scenario variants $\mathrm{A}$ and $\mathrm{B}$. The further expansion of relatively open and undisturbed subalpine forests also provides benefits such as potential habitats for the species Tetrao urogallus (A: 5300 and B: $6000 \mathrm{CHF} /$ year). If these benefits covered the whole study region, their sum would outweigh by far the estimated costs for forest maintenance (A: 9100 and B: 13,100 CHF/year (Costa 2000)). Urban sprawl into the valley floor where agriculture was abandoned would lead to a monetary loss in scenic beauty valuated at 7000 and $6200 \mathrm{CHF} / \mathrm{year}$ in scenarios A and B, respectively. The calculated changes in the monetary value of the ecosystem service "scenic beauty" may have been underestimated for the expansion of forest above the current treeline, because it could not be satisfactorily assessed in this study for the expansion of forest into abandoned land in the valley floors (Grêt-Regamey and others 2007).

\section{Discussion and Conclusions}

Within the modeling framework of ALPSCAPE, there is a high integrity between the different submodels. It combines submodels of LUA, material and energy, and the local economy, mainly by exchanging quantitative and qualitative information. The succession of the submodels involved was defined by the storyline describing the scenario. This means that, when running a new scenario, the combination of the submodels would occur in a different way. Links at the level of exchange of quantitative information are already the basis for an integrated model when calculating production, consumption and demand as a function of stocks (Alberti and Waddell 2000). The model integrity of ALPSCAPE is further improved by including the allocation of land and by including a microsimulation of actor choices (qualitative knowledge).

The links between the submodels have different degrees of robustness. The flows of quantitative information are relatively solid links, based on existing data and processes for which the main components can be modeled with simple, but robust, equations. The link between the demand for land areas and the LUA submodel introduces an uncertainty and the component of time into the model due to the stochastic and stepwise nature of the LUA submodel. This allows the result of the modeling process to be presented as "one possible change in the landscape in the future" instead of the (only) real future landscape. The goal of our research was neither to make such predictions, nor even to identify the most probable future landscape, which would have required testing the robustness of this simulation of areas allocation. Furthermore, the stepwise approach makes it possible to visualize the consequences of the scenarios for land use in different time-steps and to follow the evolution. The microsimulations of actor choices are highly dependent on scenario assumptions, and therefore the weakest links used in this framework. The structural changes in agriculture are usually identified with quantitative or comparative static optimization models, like the ones used by Lauber and others (2004) or Zgraggen and others (2005), which need detailed data on farming costs, products, and each single plot. This procedure was therefore ruled out for the purposes of our model. A possible improvement in the microsimulation of actor choices could be to assign to each category of actor type a reaction to external impulses that reflects his or her motivations. In most cases, we could assume that the objective of the actors would be to maintain or improve their turnover. These microsimulations of actor choices would then consist of listings of rules describing these reactions.

The results of our 50-year simulation reveal in various ways the relative importance of agriculture for a sustainable development of Davos. Agriculture is a long-term investment in the local economy as it preserves jobs and keeps the landscape open. Although the direct effect of agriculture on most global indicators such as employment, degree of self sufficiency, and land use could be deduced directly from the scenario in question, the effect of an open landscape on scenic beauty and touristic attractiveness must be discussed with caution. The spatially explicit model of the ecosystem service "scenic beauty" revealed no significant decrease in scenic beauty values under the assumption of our scenario. However, it has to be noted that the willingness-to-pay survey on which this model is based only accounted for land abandonment and forest expansion processes in the background of the manipulated pictures, and not in the foreground (Grêt-Regamey and others in press). This means that the changes in scenic beauty due to complete land abandonment and drastic forest expansion may have been underestimated. Other surveys suggest that open landscapes may be more appreciated by tourists than closed forests (Hunziker 1995).

Our study could help to support the claim that agriculture, by keeping the landscape open, provides other benefits that could compensate for its modest direct economic added value. More research, however, is needed to establish their economic value. The loss of jobs and the decrease in economic value of the agricultural sector might be compensated for in a minor way by a reallocation of productive resources (e.g., if farmers developed new economic 
activities, or entrepreneur and local councils used the abandoned agricultural areas for other activities). This question was not investigated in our framework, because it does not include reactive behaviors.

Some ecosystem services are potentially improved by the expansion and densification of forests (e.g., providing protection against avalanches and potential habitats), which could be used as an argument against the claim that agriculture provides benefits in keeping the landscape open. However, the spatial variability of these services in general over the Landschaft Davos means that this argument does not hold. Furthermore, this spatial variability suggests that, because current funding for forest maintenance is decreasing, it will be important to concentrate management efforts on those forest areas providing the greatest benefits. Agriculture could still have an important role to play in other areas.

The relevance of the agricultural sector for society depends on the answers to some basic questions: What does society need? What factors are important in influencing people's quality of life? How can people adapt to new situations, landscapes, habits, and so on? These questions belong more to the social sciences than to the methodologies developed in ALPSCAPE. However, we can assume that the loss of diversity in landscapes, land use, and society affects, at least in the short term, the perceptions of local residents and tourists.

Once the needs for land of each stakeholder had been identified, the model proved to be well suited to simulating a possible allocation for most land-use changes. The exception was the change from intensively to extensively exploited areas, because it did not appear in the surveys of 1985 and 1997 on which the LUA model is based. The resulting landscape change is likely to affect the habitats of animals (Laiolo and others 2004), the extent and effect of natural hazard protection (Bebi and others 2001), the potential for wood production, and, as already mentioned, the attractiveness of the landscape as perceived by tourists. We measured the attractiveness of the region with some of the indicators listed in Table 3 (not aggregated into one unique value): "Economic value of scenic beauty" for cultural landscapes; "Forest area," "Extensive agriculture area," "Unproductive vegetation area," and "Other: bare land/ water" for natural areas; "Economic value of habitat (potential habitat for the umbrella species Tetrao urogallus)" for biodiversity.

Although some results of our simulation could be seen to provide confirmation of what was already evident before, our model demonstrated this in a quantitative and spatially explicit way. It quantifies, for example, the modest direct economic added value of agriculture compared to other economic sectors or the rate of transformation of large extensively exploited areas into unproductive vegetation areas. The framework applied to our agricultural scenario also yields insights into the usefulness of different indicators, especially of ecosystem services, to evaluate the benefits of the primary economic sector.

The scenario Decrease in subsidies for mountain agriculture and liberalization of markets gives a selective view of the functions and needs of the region Davos, and of the relevant driving forces in the region. Additional important processes (e.g., related to the supply of services, forestry, and the tourist industry) are addressed in two other scenarios. In one, the effects of a mega sport event were investigated and in the other, the effects of an expected climatic change in the study area (Grêt-Regamey and others 2007, Grêt-Regamey and others in press, Grêt-Regamey and others in press, Kytzia and others in press). A larger variety of such scenarios would allow the most important driving forces for the development of a mountain region to be detected and quantified.

The framework ALPSCAPE has been designed to address specific issues for mountain tourist regions. These issues are mainly the ecological and socioeconomic impacts of tourism, climate, and land-use changes, but also conflicts and feedback mechanisms between tourism, agriculture, and the environment. We chose extreme assumptions for the scenario (subsidies totally suppressed and market totally liberalized from 2011) in order to reduce complexity and to produce significant changes in the landscape, following an approach taken in similar studies (e.g., Scholz and Tietje 2002). In order to increase the generality of the framework and to limit the technical costs, we did not include many aspects of dynamic reactive and adaptive behavior in the flow of information even though they might have improved the robustness of the model (Timmermans 2003). For the same reason, we limited the number of rules describing the possible actor choices to the required cases, without including all the possible reactions that might be relevant in other scenarios. Where data availability was limited, some parameters (e.g., the location of the land on each farm, or the number and the behavior of day-tourists) were estimated, based on local expert knowledge. Thus, the structure of this framework and the methods used in the submodels can potentially be used for any community or region, and for other scenarios. The kind of statistical data used in IOA and MFA/EFA as well as land-use data and digital maps are available for any area with administrative boundaries in Switzerland. However, when applying the framework in other areas, the selection of submodels will have to be adapted to focus on any specific regional issues, and additional surveys of local businesses would probably also be necessary.

The model ALPSCAPE in its present form offers a platform from which exact data can be extracted. The authors of the model can provide interpretations of the 
database, framework, and results for those politicians, decision-makers, and planners involved in, for example, drawing up a development plan for the next few years for the Landschaft Davos, in discussing similar problems in other mountain regions.

The model ALPSCAPE should be processed further to attain its maximum potential. Possible future developments could be as follows:

A learning tool for education, in the form of thematic packages. For such an educational tool, the modeling outcome is of interest for understanding the implications of people's decisions for the region. Additionally, the model should help the user to grasp the causal relationships between the local economy, sociology, resources, land use and the landscape, and their relative importance for regional development. Therefore, a learning tool based on ALPSCAPE would be a simplified version of this framework, emphasizing the main interrelationships and processes. Mapping a potential future landscape in a time scale of 50 years may serve as a valuable illustration of such interrelationships and processes. Furthermore, by economically evaluating the main ecosystem services produced by a region, the long-term economic gains and losses can be made clearer for the user.

A board game, where the players manage the investors, locals, and tourists in a community with the aim of developing it in a sustainable way. The idea of such a game is to learn through playing, which means that it has to be an enjoyable, imaginative, and creative game. Furthermore, the game should focus on the most important elements from the original model of Davos. This would help to maintain the central storyline of the game.

Such products are of great interest for regional planning in mountain areas and for education programs, because they can potentially guide knowledge and planning processes, and raise awareness at an early stage about unforeseen and possibly detrimental consequences of regional development over longer periods.

Acknowledgments The ALPSCAPE project is part of the Swiss National Research Program "Landscape and Habitats of the Alps" (NRP48), financed by the Swiss National Science Foundation (Nr. 4048-064441). We are grateful to Corina Lardelli, Koko Warner, and Roland Meister for valuable comments on the manuscript and to Silvia Dingwall for improving the English language.

\section{References}

Alberti M, Waddell P (2000) An integrated urban development and ecological simulation model. Integrated Assessment $1: 215-227$

Baccini P, Bader HP (1996) Regional Balance: survey, evaluation and control. [in German]. Spektrum Akademischer Verlag, Heidelberg, Berlin, Oxford
Bebi P, Kienast F, Schönenberger W (2001) Assessing structures in mountain forests as a basis for investigating the forests' dynamics and prospective function. Forest Ecol Manage 145:3-14

Beniston M (ed) (2000) Environmental change in mountains and uplands. Arnold, London

Braat LC, van Lierop WFJ (1987) Economic-ecological modeling. Elsevier, Amsterdam, The Nederlands

Costa R (2000) Das Amt für Wald Graubünden informiert...Zahlen, Fakten, Kontakte, der Bündnerwald 2000. Faktenblatt. 2nd ed. April 2000. Available at: http://www.wald.gr.ch/download/ wa_2000.pdf

Grêt-Regamey A, Susanne K (in press) Integrating the valuation of ecosystem services into input output economics of an Alpine region. Ecological Economics

Grêt-Regamey A, Bebi P, Bishop I, Schmid W (in press) Linking GIS-based models to value ecosystem services in an Alpine region. Environmental Management

Grêt-Regamey A, Bishop I, Bebi P (2007) Predicting the scenic beauty value of mapped landscape changes in a mountainous region using GIS. Envir Planning B 34:50-67

Hunziker M (1995) The spontaneous reafforestation in abandoned agricultural lands: perception and aesthetic assessment by locals and tourists. Landscape Urban Planning 31:399-410

Krausmann F, Haberl H, Erb KH, Wackernagel M (2004) Resource flows and land use in Austria 1950-2000: using the MEFA framework to monitor society-nature interaction for sustainability. Land Use Policy 21(3):215-230

Kytzia S, Nathani C (2004) Bridging the gap to economic analysis: economic tools for industrial ecology. Progr Industrial Ecol $1: 143-164$

Kytzia S, Faist M, Baccini P (2004) Economically extended-MFA: a material flow approach for a better understanding of food production chain. J Cleaner Production 12:877-889

Kytzia S, Walz A, Wegmann M (in press) How can tourism use land more efficiently? A model based approach to eco-efficiency for tourist destinations. Tourism Management

Laiolo P, Dondero F, Liliento E, Rolando A (2004) Consequences of pastoral abandonment for the structure and diversity of the alpine avifauna. J Appl Ecol 41:294-304

Lauber S, Erzinger S, Möhring A, Pfefferli S, Gehrig Schmidt S, Dietschi S (2004) Combining farm models and GIS to examine farm structures, land use and effects on landscape. Grassland Sci Eur 9:100-102

Leontief W, Carter A, Petri P (1977) The future of the world economy. Oxford University Press, New York

Maurer H (2002) Nature compatibility of dairy cows, beef, veal, pork, poultry, eggs, lamb and goat. [in German]. Available at: http:// www.konsumundnatur.ch/Lebensmitte1\%20Texte/Fleisch\% 20web.htm, accessed April 2006

Meyer WB, Turner BL (1994) Changes in land use and land cover: a global perspective. Cambridge University Press, New York

Scholz R, Tietje O (2002) Embedded case study methods. Sage Publications, London

SFOE (2000) Swiss total energy statistics. [in French]. BBL, pp 60

Swiss Agency for the Environment, Forests and Landscape (2002) Monitoring de la biodiversité en Suisse MBD. Report nr. 342. SAEFL, Bern, $88 \mathrm{pp}$

Swiss Federal Department of Economic Affairs (2005) Future evolution of the agricultural politics. Press folder of the Federal Department of Economic Affairs. [in French]. FDEA, Bern, 7pp. Available at: http://www.evd.admin.ch/imperia/md/content/ documentationdepresse/f/presserohstoff_evd_f.pdf, accessed: August 30, 2005

Swiss Federal Statistical Office (1999a) Sustainable development in Switzerland. Elements for a system of indicators. A pilot 
study after the methodology of the United Nations Commission on Sustainable Development. [in French]. FSO, Neuchatel, $111 \mathrm{pp}$

Swiss Federal Statistical Office (1999b) GEOSTAT: the service for spatial data in the Swiss Federal Administration. BFS, Neuchâtel, $16 \mathrm{pp}$

Swiss Federal Statistical Office, Swiss Agency for the Environment, Forests and Landscape (2003) Monitoring of the sustainable development MONET. Final report, Methodologies and Results. [in German]. FSO, Neuchatel, 43 pp

Timmermans H (2003) The saga of integrated land use-transport modeling: how many more dreams before we wake up? Conference keynote paper in Moving through nets: the physical and social dimensions of travel, 10-15 August 2003. Lucerne, Switzerland, $35 \mathrm{pp}$

Veldkamp A, Lambin EF (2001) Predicting land-use change. Agric Ecosystems Envir 85:1-6

von Ballmoos M, Bebi P (2003) Spatial development and sustainability in the Landschaft Davos. [in German]. Geomatik Schweiz 12:661-664

Waddell P, Borning A, Noth M, Freier N, Becke M, Ulfarsson GF (2003) Microsimulation of urban development and location choices: design and implementation of UrbanSim. Networks Spatial Econ 3:43-67

Walz A (2006) Land use modelling for an integrated approach to regional development in the Swiss Alps. $\mathrm{PhD}$ thesis. University Zürich, Zürich, 183 pp

Walz A, Bebi P, Purves RS (in press) Land-use simulation for small regions in the Swiss mountain area-comparison of two modelling techniques. In: Innovations in GIS: GIS for environmental decision making. CRC Press, Taylor \& Francis Group

Walz A, Lardelli C, Behrendt H, Lundström C, Gret-Regamey A, Kytzia S, Bebl P (2007) Merging local system knowledge and numeric regional modeling through scenario development. Landscape and Urban Planning 81:114-131

Wiek A, Binder C, Scholz RW (2006) Function of scenarios in transition processes. Futures 38:740-766

Wildi O, Ewald KC (eds) (1986) The living environment and its use in the alpine tourist area of Davos. Results of the MAB-project Davos. [in German]. Report nr. 289. Eidgenossische Anstalt für des forstliche Versuchswesen. Birmensdorf, pp 336

Zgraggen K, Flury C, Jung M, Rieder P (2005) Agricultural policy 2011-persistence, liberalization or saving? [in German]. Agrarforschung 12:156-161 